\title{
A Structurational Perspective on Leadership in Virtual Teams ${ }^{1}$
}

\author{
Robert Heckman ${ }^{1}$, Kevin Crowston ${ }^{1}$ and Nora Misiolek ${ }^{2}$ \\ 1 Syracuse University, School of Information Studies \\ 348 Hinds Hall, Syracuse, NY 13244 USA \\ Telephone: +1 (315) 443-1676, Fax: +1 866 265-7407, \\ Email: crowston@syr.edu \\ 2 Marist College School of Computer Science \& Mathematics
}

\begin{abstract}
Building on behavioural leadership theory and structuration theory, we present a two-order theory of leadership. It describes four classes of firstorder leadership behaviours (task coordination, substantive task contribution, group maintenance and boundary spanning) and defines second-order leadership as behaviour that influences changes in the structure that guides group action. We argue that second-order leadership is enabled by first-order leadership and is therefore action embedded and grounded in processes that define the social identity of the group. We propose that effective virtual teams will exhibit a paradoxical combination of shared, distributed first-order leadership complemented by strong, concentrated, and centralized secondorder leadership. We conclude by suggesting future research that might be conducted to test and further elaborate our theory.
\end{abstract}

\section{Introduction}

We develop a theory of leadership in virtual teams, networked self-organizing technology-supported small groups. Virtual teams are of great interest to organizations because of their ability to bridge discontinuities of time and geography

1 This research was partially supported by NSF Grants 04-14468 and 05-27457. Earlier versions of this paper have been presented at the First International Conference on Open Source Systems, Genova, Italy and the IFIP Working Group 8.2 Oasis Workshop. The authors acknowledge the contributions of Hala Annabi, Chengetai Masango and James Howison. 
to enable access to and transfer of knowledge across geographic and organizational boundaries, thus leveraging human and intellectual capital [1]. Because they can rapidly bring together the specific expertise needed to solve immediate problems regardless of geographical location, virtual teams also permit organizations to respond quickly to unexpected changes in the environment and to non-routine problems. As a result, virtual teams are an increasingly important part of the adaptive capability of an organization to respond to uncertainty and complexity.

Unfortunately, as teams broaden in scope and membership they become increasingly difficult to manage. In particular, members of virtual teams may come from a variety of organizations or sub-organizations; rather than being assigned to the team by a common manager, members often voluntarily choose to participate. As a result, these teams are often self-organizing, that is, they are characterized as having a "high degree of decision-making and autonomy and behavioural control at the work group level ... (such that) a much greater emphasis is placed on control from within rather than outside the group" [2]. A particularly important example of self-organizing teams are those created in the context of inter-organizational alliances where members come from different organizations but there is no dominant partner to impose a structure. Indeed, participants in virtual teams may represent no organization at all, as is often the case in Internet-enabled collaborations such as Wikipedia and Free/Libre Open Source Software (FLOSS) development teams. As organizations become increasingly knowledge-based and dependent on effective coordination of specialized knowledge for competitive advantage, teams in general, and these sorts of virtual teams in particular, grow in importance.

The primary contribution of this paper is to develop a set of theoretical propositions about the nature of emergent leadership in virtual teams based on behavioral leadership theory and structuration theory. We further develop these propositions by considering how structure can be instantiated in shared mental models and the specific behaviors that contribute to building such models. Finally, because there are interesting suggestions that can be gleaned from the nascent literature on leadership in virtual teams, we present propositions about patterns of emergent leadership that seem likely to be more effective. We focus on leadership in virtual teams for two reasons: the high level of discontinuities in virtual teams seems to pose particular challenges for leadership, and, as we discuss in our literature review, existing theories of group leadership do not seem to fully account for the leadership dynamics found in such teams. In the remainder of this subsection we describe these two problems in more detail.

First, Watson-Manheim, Chudoba \& Crowston [3] suggest that virtual work is characterized by numerous discontinuities, defined as a lack of coherence in some aspects of the work setting. Discontinuities are created and/or exacerbated by the specific features of virtual teams: often fluid organizational membership, minimized organizational context, lack of face-to-face communication, reliance on asynchronous communication, and lack of formal status cues. These discontinuities are problematic for virtual teams because they hinder team members' abilities to make sense of the shared task and of communications from others, or they produce unintended information filtering or misunderstandings [4]. The separation between 
members may ultimately result in an ineffective team $[5,6]$. Researchers have suggested that team leadership is key to helping team members overcome these barriers to performance $[7,8]$.

Second, the nature of leadership in virtual teams does not seem to be adequately described by current theories of leadership, as we will discuss in more detail in the literature review. In the absence of formally designated leaders, members within the team lead on a "voluntary" basis, either individually or collectively. In these circumstances, leadership is said to be emergent. According to Berdahl [9], leaders emerge when "one or more of a group composed initially of equal status peers . . . exhibits notably higher levels of leadership behaviour and thereby attains higher status in the eyes of fellow group members." Some virtual teams will evolve a leadership structure in which a single member emerges and is recognized by other members as the team's leader, while other teams will evolve a less-centralized leadership structure based on interaction and influence patterns. In the second kind of team, a very different form of leadership seems to be at work. No single individual plays an obviously dominant role. When asked who their leaders are, members of these teams will often say, "We have no leaders." If members of a team claim to have no leaders, is it accurate to say that the team has no leadership? Such situations pose several problems for most traditional conceptions of leadership, which is the second motivation for our paper. We argue that leadership is indeed at work in these situations, but in a form that must be looked at differently than as presented by most current theories of leadership.

In the following sections of this paper, we first introduce the two building blocks of our theorizing, leadership theory and structuration theory. We then develop a theory of emergent leadership behaviors in virtual teams. Our focus on emergent leadership leads us to try to characterize the process of emergence rather than to develop a static picture of leadership characteristics. The main contribution of our paper is the integration of various social theories to develop theoretical propositions about emergent leadership in virtual teams and, secondarily, of what patterns of leadership seem to be most effective. Our paper thus provides direction for future research by suggesting what concepts and relationships to study and what kinds of data to collect. We conclude by describing directions for future research to test or further refine and extend our theory.

\section{Theory Review}

In this section, we review research on emergent leadership in virtual teams, identify the problems these teams pose for existing theories of leadership, and suggest adopting a behavioral perspective on leadership.

\subsection{Leadership Theory}

As noted above, the presence of discontinuities in virtual teams suggests that team leadership may play a particularly crucial role in enabling team effectiveness. 
Leadership has been the topic of extensive research in the general management literature $[10,11]$. It is impossible to do justice to this voluminous literature in this paper, so our review is necessarily focused on those theories that are most applicable to our setting. Specifically, we consider only tangentially the preponderance of the literature that focuses on leadership within formal organizational hierarchies, because the nascent literature on leadership in virtual teams $[7,8,12]$ suggests that this setting differs fundamentally from leadership in virtual teams. Instead we focus on two streams of research that address in part the phenomenon of "leaderless" teams: (1) leadership in self-managing teams and shared leadership, informed by functional behavioral leadership theory, and (2) the emerging literature on leadership in virtual teams. These views of leadership depart from much of "traditional" leadership theory (for example, trait theory, contingency and situational leadership theories, social exchange and strategic contingencies theory, and leader-member exchange theories) in their basic assumptions about the nature of leaders. Specifically, these views acknowledge that leadership can be shared among team members and that more than one leader can emerge during the course of a team's interactions, rather than restricting attention to formal leadership within organizational hierarchies. In the remainder of this section, we briefly review these theories as background to our own theorizing.

Shared leadership in self-managing teams. We draw first on the concept of shared leadership, which is defined as:

A dynamic, interactive process among individuals in groups for which the objective is to lead one another to the achievement of group or organizational goals or both... (that) often involves peer, or lateral, influence and at other times involved upward or downward hierarchical influence [13].

This perspective, similar to the notion of distributed leadership [14], conceptualizes leadership in terms of relational processes and interdependencies among social networks or networks of influence [15]. It differs from conventional leadership theory by conceptualizing leadership as a group-level rather than an individual-level phenomenon. Shared leadership suggests that it is unlikely that a "single multi-role leader" will emerge. Decades of research on small team interactions supports the notion that different individuals perform different leadership roles as circumstances warrant. For example, Houghton and colleagues [16] observe that when the task-oriented and social supportive-oriented leadership roles in small teams have been examined empirically, these leadership roles are often split between two or more individuals. As a result, our research will consider that leadership may be shared rather than the responsibility of a single individual.

Misiolek \& Heckman [17] found it useful to distinguish between two types of task roles, task coordination and substantive task contribution. Task coordination behaviors are those involved in organizing and directing the team's work (scheduling, dividing labor, creating processes) while substantive task contributions are those that actually accomplish the team's work (idea generation, evaluation, synthesis) Thus, leaders may exercise their influence by means of their substantive 
expertise as well as through their coordinating and directing activities. Finally, in addition to the task and leadership functions which leadership must satisfy, Ancona and Caldwell [18] argued that there are also leadership functions involved with maintaining relations with individuals and groups outside the team, which they called boundary spanning.

Leadership in virtual teams. The nascent literature on leadership in virtual teams does provide some insights into the behavioral nature of leadership in these teams, and it has considered issues including leadership structure, initiation behavior, and communication quantity and content.

- Leadership structure. In the absence of a formal or appointed leader, the literature suggests that different leadership structures evolve within virtual teams $[17,19]$. Some teams evolve a leadership structure in which one or two emergent leaders take the initiative to structure and guide the teams' work, while others evolve a more distributed structure in which the leadership of the team is shared by its members [12, 17].

- Initiating behaviors. While only two studies examined the relationship between emergent leadership and initiation of communication, both suggest that taking initiative is associated with being identified as an emergent leader $[12,20]$.

- Quantity of communication. Findings from studies of distributed team dynamics suggest that emergent leaders communicate with team members more frequently than non-leaders $[12,17,19,21]$.

- Communication content. The literature suggests that although emergent leaders may engage in both more task-oriented and relationship-oriented communication than non-leaders, only task-oriented communication is associated with being identified as an emergent leader. Pescosolido [22] and Hart and McLeod [23] suggest that emergent leaders increase their taskoriented communication in order to reduce ambiguity, provide direction, and move the work of the team forward.

Summary. The shared leadership perspective and the results of empirical investigations of emergent leadership in virtual teams suggest that leadership can be both shared and emergent. Behavioral leadership theory provides additional insights into the classes of leadership behavior that leaders in these types of teams manifest, specifically task coordination, substantive task contribution, group maintenance, and boundary spanning [11]. However, while behavioral leadership theory provides a framework for identifying classes of leadership behaviors, it falls short in explaining changes in leadership behaviors over time in response to changes in team composition and the environment; how leadership behaviors enacted by individuals guide team interaction in these contexts; and how structures for task performance and team interaction emerge in conjunction with ongoing interaction and in the absence of a formal hierarchical authority. Understanding these dynamics is the motivation for our theorizing. 


\subsection{Structuration Theory}

To conceptualize the dynamic process by which individuals' actions can provide emergent leadership in virtual teams such as FLOSS development teams, we adopt a structurational perspective [24]. Numerous authors have used a structurational perspective to frame empirical analyses of team activities [25] and in particular, the development of virtual teams [26]. We chose this framework because it provides a recursive view of the relations between team structure and the actions of those that live within, and help to create and sustain, this structure. In particular, it provides a framework for analyzing how the leadership behaviors of one member might shape the actions of others even in the absence of traditional modes of authority.

Structuration theory is best described as a meta-theory: that is, rather than specifically describing the relations between particular factors of leadership, structuration theory describes the form that such a theory should take. Specifically, structuration theory suggests that a theory of leadership in virtual teams should consider structure and action in these teams and how the two are interrelated. By structure, we mean the rules and resources that influence, guide, or justify individual action. Structure is "encoded in actors' stocks of practical knowledge" [27] and "instantiated in recurrent social practice" [28]. In our work, we consider three kinds of rules and resources identified in prior work [27, 29]: (1) interpretive schema that create structures of signification, (2) authoritative and allocative resources that create structures of domination, and (3) norms and rules that create structures of legitimation. Individual actions may be guided by these structures or may seek to change them, as will be discussed further below.

Structure matters because the development of shared structure improves team performance if it enables more effective contributions by team members. That is, it is not a question of the presence or absence of structure, but rather its nature and the degree of agreement among team members. For example, without common interpretive schema (a kind of shared structure), individuals from different teams or backgrounds may interpret tasks differently based on their backgrounds, making collaboration and communication difficult [30]. The tendency for individuals to interpret tasks according to their own perspectives and predefined routines is exacerbated when working in a distributed environment, with its more varied individual settings and less opportunity for informal discussion.

We turn now to the question of how structure is developed. The key notion here is the "duality of structure," meaning that the structural properties of a social system are seen as both the means and the ends of the practices that constitute the social system. As Sarason [31] explains, in structuration theory:

The central idea is that human actors or agents are both enabled and constrained by structures, yet these structures are the result of previous actions by agents. Structural properties of a social system consist of the rules and resources that human agents use in their everyday interaction. These rules and resources mediate human action, while at the same time they are reaffirmed through being used by human actors or agents. (p. 48). 
Simply put, by doing things, we create the way to do things. Or as Askehave \& Swales [32] put it more poetically, "the wheels of life go round, and as they go round, they form ruts which channel the wheels of life."

Figure 1, adapted from Barley and Tolbert [27], graphically summarizes the relation between institution (which the authors use synonymously with structure) and action, and how both evolve over time. In this figure, the two bold horizontal lines represent "the temporal extensions of Giddens' two realms of social structure: institutions and action," while the "vertical arrows represent institutional constraints on action" and the diagonal arrows, "maintenance or modification of the institution through action" (p.100). For example, the influence of a team norm on a developer to use a particular testing strategy is represented by a downwards vertical arrow, while reinforcement or changes to the norm, due to actions, is represented by an upwards diagonal arrow. We use this model of action and structure as the basis for our theorizing about the nature of leadership in virtual teams.

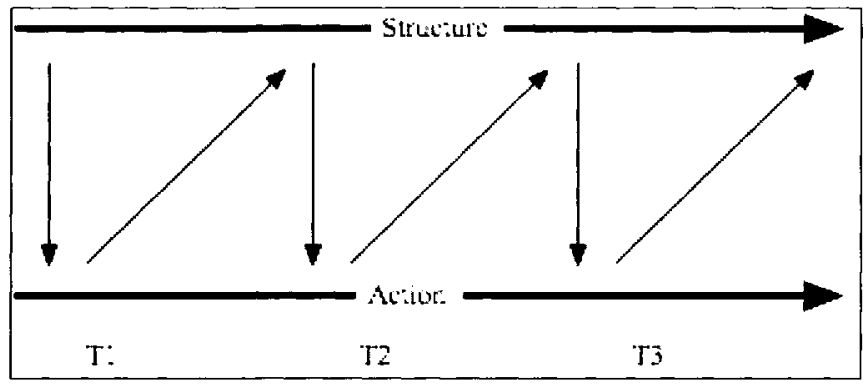

Figure 1: A sequential model of the relation between structure and action.

\section{Theory Development: Emergent Leadership in Virtual Teams}

In the following section we develop an argument that emergent leadership in virtual teams consists of behaviors that generate or reinforce structure (the upwards diagonal arrows in Figure 1). While it might first appear that a consideration of leadership would be relevant primarily to an understanding of structures of domination, we propose that leadership in virtual teams is expressed through all three systems of structure: signification, domination, and legitimation. Indeed, leaders of virtual teams may lack formal control over authoritative and allocative resources that produce structures of domination. Instead, based on the combination of functional behavioral leadership theory and structuration theory reviewed above, we argue that a key role of emergent leadership in virtual teams is the development of the full range of structures that guide the actions of team members and overcome the challenges created by discontinuities. Thus we define leadership in this context as:

Definition. Leadership in virtual teams is a process that results in the reinforcement, creation and ongoing evolution of team structures. 
Based on this definition, we present four propositions that describe the specific aspects of the nature of emergent leadership in virtual teams and follow with a set of research questions for future study.

\subsection{A Two-order Theory of Emergent Leadership in Virtual Teams}

If leadership in virtual teams is a process that results in the reinforcement, creation and ongoing evolution of structures, how does this process operate? The structurational perspective suggests that some actions serve to reinforce existing structures, while others have the effect of modifying structures. It therefore suggests discriminating between two orders of leadership: one that influences team member behavior while maintaining existing structures (first-order) and one that works by modifying team structures (second-order). Thus we propose that leadership in virtual teams operates on two, interrelated levels:

Proposition 1: Leadership in virtual teams operates on two levels. First-order leadership is predominantly functional. It operates within the constraints of, and reinforces existing structures. Second-order leadership is predominantly transformational, and operates to modify or transform structures as needed.

The functional theories of leadership reviewed above identified four classes of leadership behaviors that we view as first-order leadership: (1) task coordination, (2) substantive task contribution, (3) group maintenance, and (4) boundary-spanning. These behaviors are especially important in virtual teams. Because such teams lack the formal, hierarchical supervisory structure that assumes much of the coordination burden in traditional teams, they are highly dependent on the emergence of effective and adaptive first-order leadership behaviors. Rather than following a division of labor based on the direction of a manager, team members decide for themselves what they will do (and not do), based in part on observations of what others are doing (and not doing). Most importantly, first-order leadership influences team members by reinforcing existing structures that shape and constrain team member action.

Second-order leadership, on the other hand, is a process that results in modifications to the structures of signification, domination, and legitimation. While first-order leadership influences team member behavior within the given constraints of existing structures (and thereby serves to reinforce them), second-order leadership effects change in the structures. The distinction between first-order and second-order leadership is analogous to the distinction between single-loop and double-loop learning as proposed by Argyris and Schon [33], and the distinction between firstorder and second-order change as described by Watzlawick, Weakland and Fisch [34].

Nature of first-order leadership. Positing a distinction between first-order and second-order leadership raises two primary questions that inform our research. First, we propose to identify the patterns of first-order and second-order leadership that emerge in virtual teams, and, second, of those that emerge, which are likely to be most successful. Propositions 2 and 3 address these questions. 
First, we consider the pattern of first-order leadership. Research has documented that different teams faced with similar contextual and task demands often evolve very different role and leadership structures and different work practices [17, 35]. For example, in one study [17], virtual teams working on identical tasks within a controlled context developed very different functional leadership structures, some highly centralized with one or two strong leaders performing leadership behaviors, and others highly decentralized with leadership behaviors widely distributed [17]. We expect the teams that say they have no leaders may instead have a form of shared leadership where first-order leadership is widely distributed among the team's members.

However, we propose that decentralized first-order leadership will lead to more effective virtual teams. First, research on face-to-face teams [36] suggests that the same individual is unlikely to perform all four functional leadership roles equally well. Second, teams that attempt to integrate diverse, specialized knowledge workers [37] may require many different kinds of first-order leadership in the form of substantive task contribution. Finally, the voluntary, self-organizing nature of many virtual teams may create other pressures for distributed first-order leadership. In the area of task coordination, for example, self-assignment is often the predominant mode in which division of labor is accomplished [38], a significant difference from the centralized, hierarchical task assignment mechanism found in traditional organizations. In short, the discontinuities that characterize virtual teams create a pressure for distributed first-order leadership. We thus offer the following:

Proposition 2: First-order leadership can be either centralized or distributed, however, it is more likely to be fluid, distributed, emergent, and widely shared in effective virtual teams.

Nature of second-order leadership. We next consider the pattern of second-order leadership. As with first-order leadership, we propose that virtual teams will evolve a variety of second-order leadership structures, but in the case of second-order leadership, we propose that a more centralized or concentrated form will be associated with effectiveness in the long run. That is, we propose that the most effective virtual teams will be characterized by a leadership structure that includes widely distributed and shared first-order leadership complemented by strong, centralized second-order leadership. We argue that centralized second-order leadership will be more effective because of the need for clarity and agreement among team members about the important social structures that govern and constrain their behavior. To be effective, teams must have a high degree of shared consensus about structures of signification, domination, and legitimation. This is more likely to occur in teams that have strong leaders who are able to clearly articulate a vision of these structures that is broadly embraced by team members. Studies by Kayworth and Leidner [39] and Piccoli et al. [19] suggest that the most effective virtual teams were those in which one or two team members took the initiative to clarify team members' responsibilities and work process structures. We thus offer the following:

Proposition 3: Second-order leadership can be either centralized or distributed, however, it is more likely to be centralized in effective virtual teams. 
Relationship between first and second-order leadership. Whether second-order leadership is highly concentrated and centralized or widely distributed and shared, a fundamental question remains: How do those who are able to influence change in underlying team structures gain the power to do so (i.e., why are some actions structure changing and others not)? We propose that the answer to this question lies in the nature of the interrelationship between first-order and second-order leadership. Our preliminary observations suggest that second-order leadership is action embedded. By this we mean that second-order leadership derives its authority not from communication alone, but from substantive, action-oriented contribution. Such substantive contribution will take different forms depending on the task and mission of any given team. We thus offer the following:

Proposition 4: First-order leadership behavior, especially substantive task contribution, is a prerequisite for second-order leadership behavior. Members acquire "permission" to be second-order leaders by performing first-order leadership behaviors.

This proposition, about how individuals accumulate the authority to lead in virtual teams, appears to conflict with commonly accepted theories of power that equate power with the capacity to influence team members. In this view, the ability to be a second-order leader (to influence change in social structures) is a function of the power an individual has accumulated. In the standard theories of power, this capacity is thought to derive from the control of resources that are valued or desired by others. Team members are believed to be dependent on resources controlled by the influencer for need satisfaction or goal achievement, and are thus they are willing to grant power [40]. In short, control of resources and resource dependence produces power and power is the source of influence. However, this approach has recently been challenged by a social identity model of leadership and power [40], which reverses the causal sequence. The social identity model argues that it is psychological group formation that produces influence, and that power and control of resources derives from influence [40]. In self-organizing virtual teams, control of resources and dependence are problematic concepts, because team members are often volunteers who are free to work as little or as much as they like and to leave the team at any time. Thus the social identity model theoretically supports the actionembedded nature of second-order leadership we have observed.

\subsection{Shared Mental Models as Structure}

The theory we have developed above describes effective leadership in virtual teams as a process that results in the reinforcement, creation and ongoing evolution of effective structure. To further develop our theory of effective leadership in virtual teams, we must identify the particular second-order leadership behaviors that create and evolve structure. To do so, we need to examine in more detail the constitution of structure in virtual teams. Schein [41] argues that structure reflects still deeper levels of shared basic assumptions and beliefs (which he considers the deepest levels of culture). We suggest that these shared assumptions and beliefs can be viewed as forming shared mental models. Shared mental models, as defined by Cannon- 
Bowers \& Salas [42], "are knowledge structures held by members of a team that enable them to form accurate explanations and expectations for the task, and in turn, to coordinate their actions and adapt their behavior to demands of the task and other team members." (p. 228)

The issue is not so much whether team members have mental models, but rather the degree of similarity among the models of team members. Prior research suggests that the existence of accurate shared mental models that guide member actions are important for team effectiveness [42]. Leadership in virtual teams therefore can be seen as an influence process that results in the creation, maintenance, and ongoing evolution of accurate shared mental models, and effective leadership translates into creating such shared mental models. Thus, we share with Schein [41] the notion that a primary operation of leadership is the transmitting and embedding of shared cognitions through the development and modification of shared mental models.

\subsection{Summary}

In summary, we argue that second-order leadership consists of behaviors that build accurate shared mental models in the form of commonly accepted interpretive schema, role structures and rules and norms for behavior. The propositions above suggest that second-order leaders will be those individuals that contribute to socialization, conversation and recapitulation to build effective shared interpretive schema; to task division and decision process development to build effective shared role structures; and to collaborative, interactive problem solving, political negotiation, and experiential learning to build effective shared rules and norms.

Is such change incremental or discontinuous? Advocates of double-loop learning [33] believe that change in underlying structures is only possible when groups have consciously reflected on conditions eliciting a need for change, have surfaced the group's deep assumptions and beliefs, and engaged group consensus for change. In effect, double loop learning theory requires that group members be consciously aware of team structures before they are able to change them. Before changes in theory-in-use (the tacit structures that govern behavior) are possible, members "require external references. There must be public representations of organizational theory-in-use to which individuals can refer .... These are the shared descriptions of the organization which individuals jointly construct and used to guide their own inquiry" [33].

In contrast to this highly rational, discontinuous change model, we propose that the structural change influenced by second-order leadership may sometimes also result from a more incremental, subconscious process. For example, a team's role structure may gradually evolve as the overall task of developing the system is divided into pieces suitable for different kinds of participants. The job of coordinating task assignment is an example of first-order leadership, and much of this work will be distributed self-assignment-individuals voluntarily taking on tasks for which they have particular skills or interest. But as the role structure evolves, second-order leadership will call attention to and clarify the newly emergent 
structure, and influence the group to embrace it. The process of consciously surfacing and describing underlying structures may not be necessary in our context because in virtual teams using information and communication technology to collaborate the transparent dialogues themselves, archived for subsequent viewing as they are, become the external reference called for by Argyris and Schon [33], the public representation of organizational theory in use to which individual members can refer.

\section{Discussion}

In this paper we have presented a two-order theory of leadership in virtual teams, using an approach built on a foundation of structuration theory and functional, behavioral leadership theory. Because functional leadership theory does not fully explain the relationship between leadership and group change, we have expanded upon it to include the notion of second-order leadership, a form of leadership that influences changes in the structure that guides group behavior. We have proposed that effective virtual teams will exhibit a paradoxical combination of widely shared, distributed first-order leadership complemented by strong, concentrated, and centralized second-order leadership. Finally, we have proposed that second-order leadership is enabled by first-order leadership, is therefore action embedded, and is grounded in processes that define the social identity of the team.

We conclude this paper by discussing several methodological issues and possible research questions to guide future systematic inquiry. We have described the process of leadership in virtual teams as an influence process leading to the development, maintenance, and evolution of accurate shared mental models. A variety of research approaches could be applied to study this process. Use of interview data would enable exploration of the group members' perceptions of the leadership process and allow direct comparison between different members' mental models, thus explicitly examining how shared models are developed. On the other hand, content analysis of the interactions between members of virtual teams would enable detailed analysis of the influence process as it unfolds. Such analysis infers the deep structures and processes from informed examinations of the artifacts that these surface level dialogues provide. This approach has the advantage of avoiding reliance on the recollections of team members, which may degrade over time or be unreliable in other ways. However, two guidelines for such research should be kept in mind. First, observations should be longitudinal and dynamic, carefully observing changes that occur over time. The phenomenon of leadership is inherently rooted in the passage of time and cannot be observed in a snapshot. As a structurational process, it can only be seen through a longitudinal lens. Second, the unit of coding and analysis in such research should be the episode. Leadership is fundamentally an interaction process between leaders and followers, and such interactions are best observed episodically.

The two-order leadership theory and propositions we have presented suggest several specific research questions to be addressed in our future work, and these questions apply to the study of effective leadership of virtual teams more generally: 
$R Q 1$. What are the dimensions of first-order leadership? Building on functional leadership theory, we have proposed that first-order, functional leadership consists of four classes of behavior: (1) coordination, (2) substantive task contribution, (3) group maintenance, and (4) boundary-spanning. Future research should assess whether these four dimensions provide a relatively comprehensive description of first-order leadership.

$R Q$ 2. What patterns of first-order leadership emerge in virtual teams? In previous research on leadership in virtual teams [17], we observed that very different patterns of first-order leadership can exist in different teams. While we have discussed centralized versus decentralized leadership patterns, such a distinction may prove to be too simple to fully describe the leadership patterns that emerge in various types of virtual teams. Future research should classify the first-order leadership patterns that emerge in order to develop valid and reliable operational definitions of centralized and decentralized patterns.

$R Q$ 3. How do patterns of first-order leadership evolve over time? Leadership is not a static phenomenon. As teams grow and attract new members, lose existing members, or face new environmental constraints, leadership patterns may change. For example, in our current study of FLOSS teams [43], we observed growing levels of participation in decision-making in one project and declining levels of participation in another. A longitudinal research design will be necessary to systematically observe and understand such dynamic changes in leadership patterns.

$R Q$ 4. What aspects of structure are most important to observe in order to understand second-order leadership, and what is the nature of this structure? We have described structures of signification, domination, and legitimation that exist in virtual teams, and we have suggested that shared mental models underlie all three types of structures. Again, the observation of various types of virtual teams will allow us to inductively infer and classify these structures, better understand their nature, and their instantiation in actions.

$R Q 5$. How does second-order leadership influence change in team structures? Some scholars [33] suggest that deep structures are best modified by a rational, discontinuous change process that includes discovery of hidden beliefs and assumptions (structures), followed by a consensus-based examination of and experimentation with potential new structures. Others suggest that the change process might be less rational and more emotional, less discontinuous and more incremental, and action-embedded rather than communication-driven. Schein [41] noted that some of the most powerful mechanisms for embedding and reinforcing culture are based on leaders' actions - what they pay attention to, reward, sanction, and their reaction to critical incidents and crises.

$R Q 6$. How do second-order leaders gain influence? We have proposed that second-order leaders gain influence by virtue of their action-embedded first-order leadership contributions. We also suggested that this process is more consistent with the social identity model of power than with the traditional resource dependence models of power. These assertions require systematic testing that will best be accomplished through detailed longitudinal observations of numerous virtual teams. 
$R Q 7$ 7. How do different patterns of leadership (both first-order and secondorder) relate to team effectiveness? Once we have inductively classified the firstorder and second-order leadership patterns that emerge and have developed valid and reliable operational definitions of these patterns, we will be in position to test the proposition that the most effective virtual teams will exhibit decentralized first-order leadership and centralized second-order leadership.

$R Q 8$. What are the boundaries to first-and second-order leadership? We have argued that first-order and second-order leadership involve reliance on and changes to shared mental models. However, such models are never shared perfectly and so may present a boundary to the influence of this form of leadership. On the other hand, Kellogg et al. [44] note that coordination does not require equivalence or similarity of interpretations; rather, different teams can agree on "general procedures of exchange even while they may have different local interpretations of the objects being exchanged" (p. 39). The onion-like structure in FLOSS teams [45] provides an interesting setting to explore this question. We expect core members to have a high level of commonality in their mental models, but that this commonality will decrease in less active members.

The theory and propositions we have developed represent an attempt to integrate and consolidate several previously developed theoretical perspectives on leadership and group dynamics in virtual teams. We hope that this will provide a starting point for future research and thereby make a contribution to the study of virtual teams within the organization literature. We note that while we are particularly interested in virtual teams in which leadership is emergent, we believe that these propositions may also apply to cases in which leadership is assigned.

\section{Conclusion}

The primary contribution of this paper has been to develop a set of theoretical propositions about the nature of effective leadership in virtual teams. However, even in its nascent state our theory has some implications for the practice of leading small groups. The theory suggests specific actions that members of technology-supported distributed small groups can take to improve performance. These include ensuring that all first-order leadership functions are performed well and preferably by many team members in a decentralized mode. It also suggests that there is value in centralizing second-order leadership functions. Virtual teams might more explicitly recruit or select members who are particularly skilled at these functions and pay more attention to the on-going process of developing shared interpretive schema, role structures and rules and norms. More generally, educational programs for all kinds of workers might incorporate these ideas. For example, distance education classes that use technology support for instruction should provide instruction for students on the nature of leadership in virtual teams and thus set expectations for how the work can best be accomplished, as well as requiring team projects to provide an opportunity to practice these skills. 
Whether these propositions are confirmed or disconfirmed by future research, understanding how teams of independent knowledge workers can more effectively work in virtual environments will improve both the traditional and non-traditional organizations within which they exist. The results of the research we hope to stimulate will then serve as a road map to improve organizational performance and foster innovation.

\section{References}

1. D. L. Duarte and N. T. Snyder, Mastering Virtual Teams $\left(2^{\text {nd }}\right.$ ed) (Jossey-Bass, San Francisco, 2001).

2. C. C. Manz and H. P. Sims, Jr., Leading Workers to Lead Themselves: The External Leadership of Self-managing Work Teams, Administrative Science Quarterly 32, $106-$ 128 (1987).

3. M. B. Watson-Manheim, K. M. Chudoba, and K. Crowston, Discontinuities and Continuities: A New Way to Understand Virtual Work, Information, Technology and People 15(3), 191-209 (2002).

4. D. J. Armstrong and P. Cole, Managing Distance and Differences in Geographically Distributed Work Groups, in: Distributed Work, edited by P. Hinds and S. Kiesler (MIT Press, Cambridge, MA, 2002), pp. 167-186.

5. E. Carmel and R. Agarwal, Tactical Approaches for Alleviating Distance in Global Software Development, IEEE Software (March/April), 22-29 (2001).

6. R. E. Kraut, C. Steinfield, A. P. Chan, B. Butler, and A. Hoag, Coordination and Virtualization: The Role of Electronic Networks and Personal Relationships, Organization Science 10(6), 722-740 (1999).

7. W. F. Cascio and S. Shurygailo, E-leadership and Virtual Teams, Organizational Dynamics 31(4), 363-376 (2003).

8. I. Zigurs, Leadership in Virtual Teams: Oxymoron or Opportunity?, Organizational Dynamics 31(4), 339-351 (2003).

9. J. L. Berdahl, Gender and Leadership in Work Groups: Six Alternative Models, Leadership Quarterly 7(1), 21-40 (1996).

10. B. M. Bass, Bass \& Stogdill's Handbook of Leadership (Free Press, New York, ed. 3rd, 1990).

11. G. Yukl, Leadership In Organizations (Prentice Hall, Upper Saddle River, NJ, ed. 5th, 2002).

12. Y. Yoo and M. Alavi, Emergent Leadership in Virtual Teams: What Do Emergent Leaders Do?, Information and Organization 14, 27-58 (2004).

13. C. L. Pearce and J. A. Conger, Eds., Shared Leadership: Reframing the Hows and Whys of Leadership (Sage, Thousand Oaks, CA, 2003), pp.

14. P. Gronn, Distributed Leadership as a Unit of Analysis, The Leadership Quarterly 13(4), 423-451 (2002).

15. J. K. Fletcher and K. Kaufer, Shared Leadership: Paradox and Possibility, in: Shared Leadership: Reframing the Hows and Whys of Leadership, edited by C. L. Pearce and J. A. Conger (Sage, Thousand Oaks, CA, 2003), pp. 21-47. 
16. J. D. Houghton, C. P. Neck and C. C. Manz, Self-leadership and Superleadership, in: Shared Leadership: Reframing the Hows and Whys of Leadership, edited by C. L. Pearce and J. A. Conger (Sage, Thousand Oaks, CA, 2003), pp. 123-140.

17. N. Misiolek and R. Heckman, Patterns of Emergent Leadership in Virtual Teams, in: Proceedings of the 38th Hawaii International Conference on System Sciences (HICSS 2005), (Big Island, HI, 2005).

18. D. G. Ancona and D. F. Caldwell, Beyond Task and Maintenance: Defining External Functions in Groups, Group and Organization Studies 13, 468- 494 (1988).

19. G. Piccoli, A. Powell, and B. Ives, Virtual Teams: Team Control Structure, Work Processes, and Team Effectiveness, Information, Technology \& People 17(4), 359-379 (2004).

20. K. L. Tyran, C. K. Tyran, and M. Shepherd, Exploring Emergent Leadership in Virtual Teams, in: Virtual Teams That Work: Creating Conditions for Virtual Team Effectiveness, edited by C. B. Gibbon and S. G. Cohen (Jossey-Bass, San Francisco, 2003), pp. 183-195.

21. S. L. Jarvenpaa and D. E. Leidner, Communication and Trust in Global Virtual Teams, Organization Science 10(6), 791-815 (1999).

22. A. T. Pescosolido, Emergent Leaders as Managers of Group Emotion, Leadership Quarterly 13, 583-599 (2002).

23. R. K. Hart and P. L. McLeod, Rethinking Team Building in Geographically Dispersed Teams: One Message at a Time, Organizational Dynamics 31(4), 352-361 (2003).

24. A. Giddens, The Constitution of Society: Outline of the Theory of Structuration (University of California, Berkeley, 1984).

25. S. R. Barley, Technology as an Occasion for Structuring: Evidence from the Observation of CT Scanners and the Social Order of Radiology Departments, Administrative Sciences Quarterly 31, 78-109 (1986).

26. S. Sarker, F. Lau, and S. Sahay, Using an Adapted Grounded Theory Approach for Inductive Theory Building About Virtual Team Development, DATA BASE for Advances in Information Systems 32(1), 38-56 (2001).

27. S. R. Barley and P. S. Tolbert, Institutionalization and Structuration: Studying the Links Between Action and Institution, Organization Studies 18(1), 93-117 (1997).

28. W. J. Orlikowski, Using Technology and Constituting Structures: A Practice Lens for Studying Technology in Organizations, Organization Science 11(4), 404-428 (Jul-Aug, 2000).

29. E. W. Stein and B. Vandenbosch, Organizational Learning During Advanced System Development: Opportunities and Obstacles, Journal of Management Information Systems 13(2), 115-136 (1996).

30. D. Dougherty, Interpretive Barriers to Successful Product Innovation in Large Firms, Organization Science 3(2), 179-202 (1992).

31. Y. Sarason, A Model of Organizational Transformation: The Incorporation of Organizational Identity into a Structuration Theory Framework, Academy of Management Journal (Best papers proceedings), 47-51 (1995).

32. I. Askehave and J. M. Swales, Genre Identification and Communicative Purpose: A Problem and a Possible Solution, Applied Linguistics 22(2), 195-212 (2001).

33. C. Argyris and D. A. Schön, Organizational Learning (Addison-Wesley, London, 1978). 
34. P. Watzlawick, J. Weakland, and R. Fisch, Change: Principles, Problem Formulation and Problem Resolution (Norton, New York, 1974).

35. S. L. Brown and K. Eisenhardt, M., The Art of Continuous Change: Linking Complexity Theory and Time-paced Evolution in Relentlessly Shifting Organizations, Administrative Sciences Quarterly 42(1), 1-34 (1997).

36. R. F. Bales, A Set of Categories for the Analysis of Small Group Interaction, American Sociological Review 15(2), 257-263 (1950).

37. R. M. Grant, Toward a Knowledge-based Theory of the Firm, Strategic Management Journal 17(Winter), 109-122 (1996).

38. K. Crowston, K. Wei, Q. Li, U.Y. Eseryel, and J. Howison, Coordination of Free/Libre Open Source Software development, paper presented at the International Conference on Information Systems (ICIS 2005), Las Vegas, NV, USA 2005.

39. T. R. Kayworth and D. E. Leidner, Leadership Effectiveness in Global Virtual Teams, Journal of Management Information Systems 18(3), 7-40 (2002).

40. J. C. Turner, Explaining the Nature of Power: A Three Process Theory, European Journal of Social Psychology 35, 1-22 (2005).

41. E. H. Schein, Organizational Culture and Leadership (Josey-Bass, San Francisco, 1987).

42. J. A. Cannon-Bowers and E. Salas, Shared Mental Models in Expert Decision Making, in: Individual and Group Decision Making, edited by N. J. Castellan (Lawrence Erlbaum Associates, Hillsdale, NJ, 1993), pp. 221-246.

43. R. Heckman et al., Emergent Decision-making Practices in Technology-supported Selforganizing Distributed Teams, in: Proceedings of the International Conference on Information Systems (ICIS 2006), (Milwaukee, WI, 10-13 Dec, 2006).

44. K. C. Kellogg, W. J. Orlikowski, and J. Yates, Life in the Trading Zone: Structuring Coordination Across Boundaries in Postbureaucratic Organizations, Organization Science 17(1), 22-44 (2006).

45. K. Crowston and J. Howison, The Social Structure of Free and Open Source Software Development, First Monday 10(2) (2005).

\section{About the Authors}

Dr. Robert Heckman is Associate Professor and Director of the Graduate Program in Information Management at the School of Information Studies, Syracuse University. His current research is focused on effective use of asynchronous learning networks, leadership in virtual teams, and discretionary technology-mediated collaboration. He received his Ph.D. in Information Systems from the University of Pittsburgh in 1993.

Kevin Crowston is a Professor in the School of Information Studies at Syracuse University. His research focuses on new ways of organizing made possible by the use of information and communications technology, including in particular virtual teams and organizations. He approaches this issue in several ways: empirical studies of coordinationintensive processes in human organizations; theoretical characterizations of coordination problems and alternative methods for managing them; and design and empirical evaluation of new kinds of computer systems to support people working together. 
Nora I. Misiolek is Assistant Professor of Information Systems in the School of Computer Science and Mathematics at Marist College. She earned her doctorate in Information Science and Technology from the School of Information Studies at Syracuse University, and holds an M.B.A. in Innovation Management and Marketing from the Whitman School of Management, also at Syracuse. Her research interests include virtual teams and collaboration, influence of information technologies on innovation, and technological entrepreneurship. 